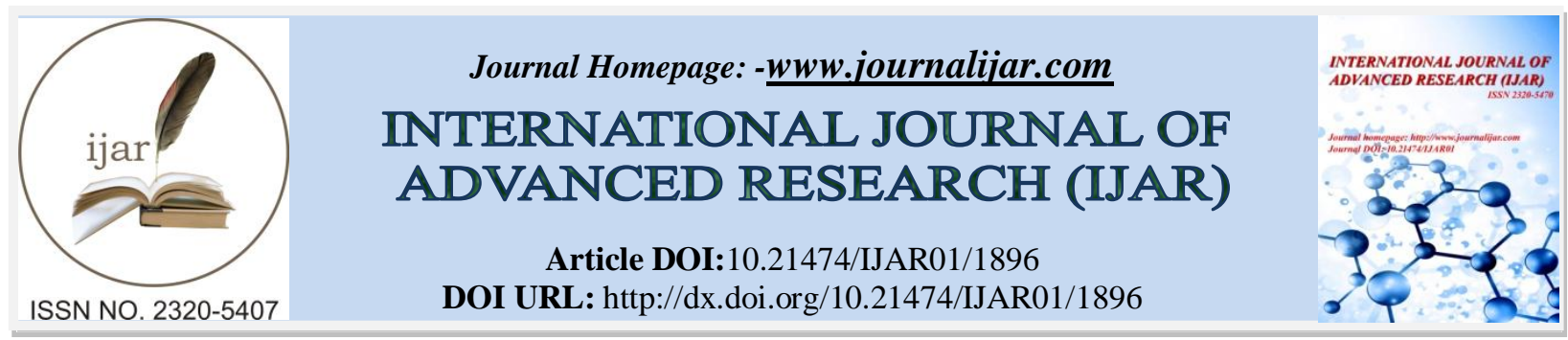

RESEARCH ARTICLE

\title{
PREHYPERTENSION ;THE POINT OF CONVERGENCE OR DIVERGENCE FOR END ORGAN DAMAGE
}

Manar. M. Al- Zaki MD, Mohammad Gouda MD and Marwa Gad MD. Department of Cardiology, Faculty of Medicine, ZagazigUniveristy Hospital, Egypt.

\section{Manuscript Info}

Manuscript History

Received: 12 August 2016

Final Accepted: 13 September 2016

Published: October 2016

Key words:-

prehypertension, Ambulatory BP monitoring ,QT dispersion .Left

Ventricular mass .

\section{Abstract}

Background and Aim of work:- In hypertensive people, left ventricular hypertrophy (LVH) can anticipate an expanded morbidity $\&$ sudden death, which is up to ten times more common in people with left ventricular hypertrophy (LVH) than those without. To investigate the extent to which prehypertension may be associated with preclinical target organ damage (TOD) so we comprehensively investigated the association of prehypertension with parameters of left ventricular (LV) structure and function .

Patients\& methods:- This prospective study was carried out in cardiology department, Zagazig University in the period from August 2014 to October 2015. This study included two groups classified by ambulatory BPmonitoring (ABPM) to exclude masked hypertension and by serial office blood pressure measurement :Prehypertensive (G1) and control (G11).

Result:- Compared to participants with optimal BP, those with prehypertension had a nominally higher prevalence of abnormal LV geometry increased left ventricular mass index (LVMI) cutoff point of QT dispersion $\geq 40 \mathrm{~ms}$ indicate presence of increased LVMI with sensitivity $=\mathbf{7 6 . 2 6} \&$ specificity $=\mathbf{5 7 . 7 8}$

The mean adjusted LV mass was significantly greater in prehypertensive $\left(193.65 \pm 41.14 \mathrm{~g} / \mathrm{m}^{2}\right.$ vs. $\left.159 \pm 35.56 ; \mathrm{p}<0.001\right)$.

Conclusion:- Increased efforts regarding education, detection, and treatment could be important in management ofpre hypertension and cardiovascular disease risk prevention.

Copy Right, IJAR, 2016,. All rights reserved.

\section{Introduction:-}

Eighth Report of the Joint National Committee (JNC-8) gives a more up to date guidelines on classification of HTN, SBP between 120-139 $\mathrm{mmHg}$ and/or DBP between 80-89 $\mathrm{mmHg}$ fall into prehypertension \& have higher cardiovascular \& renal danger in future(James et al., 2014)

In hypertensive people, left ventricular hypertrophy (LVH) can anticipate an expanded morbidity \& sudden death, which is up to ten times more common in people with left ventricular hypertrophy (LVH) than those without.

(Armstrong et al., 2012).

Parameters of left ventricular (LV) repolarization and its inhomogeneity, such as prolonged QT interval and its dispersion (QTd), have been associated with poor prognosis in different clinical settings, including essential HTN, 
QTd is increased in association with increased left ventricular mass index in hypertensive individuals (Antonakis et al., 2014).

To investigate the extent to which prehypertension may be associated with preclinical target organ damage (TOD), we investigated the association of prehypertension with parameters of left ventricular (LV) structure and function

\section{Patients \&Method:-}

This prospective study was carried out in cardiology department, Zagazig University in the period from August 2014 to October 2015. This study included two groups classified by ambulatory BP to exclude masked hypertension as:

1. Group I: high normal BP $(130-139 / 85-89 \mathrm{mmHg})(n=158)$,

2. Group II (control group): normotensive: normal BP $(<120 / 80 \mathrm{mmHg})(n=146)$. According to the JNC-8 recommendations (James et al., 2014).

\section{Inclusion criteria:-}

This study included both male and female normal subjects below the age of 65 who visited our out- patient clinics with no history of hypertension or other conditions known to affect LVM and QT interval or QTd, normal cardiac physical examination.

\section{Laboratory tests:-}

Kidney function test (serum creatinine, urea and eGFR) and micro-albuminuria.

\section{Kidney function test:-}

1. Serum creatinine was measured using Cobas 6000 C501 electrochemiluminescent assay.

2. Glomerular filtration rate (eGFR) was calculated using Cockcroft-Gault equation for creatinine clearance estimation:

eGFR= sex X (140 - age(years)) $X$ body weight $(\mathrm{Kg}) / 72 \mathrm{X}$ s.creatinine.

Sex : male (1) - female (0.85)(Cockcroft \& Gault, 1976).

\section{Micro-albuminuria:-}

Morning mid-stream urine samples were collected from all subjects and analyzed using DIRUI H-500 urine analyzer. Results between 30-200 mg/L indicates clinical micro-albuminuria .

Twelve-lead surface Electrocardiography:-

All subjects had a resting simultaneous 12-lead electrocardiogram (ECG) using an ATM-101 Power electrocardiograph machine.

\section{QT dispersion measurement:-}

All ECGs were analyzed by two different observers blinded to the clinical data. QT and the preceding RR intervals were assessed manually with calipers and mean values were determined in three consecutive cycles.

QT dispersion (QTd) in milliseconds was defined as the difference between the shortest (QTmin) and longest (QTmax) in each electrocardiogram

QTd= 30-60 ms were considered normal (Sahu et al, 2000).

\section{LVH criteria on ECG:-}

Cornell voltage criterionwas used to detect LVH:

Summation of (S) wave in lead V3 and (R) wave in lead avl on twelve leads surface ECG as following:

$\mathrm{SV} 3+\mathrm{RaVL} \geq 2.8 \mathrm{mV}$ (for men)

$\mathrm{SV} 3+\mathrm{RaVL}>2.0 \mathrm{mV}$ (for women)

\section{(Mirvis\& Goldberger, 2015)}

Ventricular activation time (VAT):-

VAT was measured in $\mathrm{ms}$ in the 12 leads and was defined as the average measurement from the onset of the Q wave to the peak of the R wave (QR interval) or the measurements from V6 (Boles et al., 2010). 


\section{Conventional Trans-thoracic Echo-doppler study:-}

Transthoracic echocardiographic examination was done to all patients using HP SONOS (USA) and GE Vivid E9 (Norway) set with a $2.5 \mathrm{MHz}$ transducer. Images were taken while the patient in supine or in the left lateral position.

\section{LVMI measurement:-}

According to the American Society of Echocardiography (ASE) recommendations, the following measurements were obtained:

left ventricular internal diameter in diastole (LVIDd), left ventricular internal diameter in systole (LVIDs), interventricular septal thickness in diastole (IVSTd) and left ventricular posterior wall thickness in diastole (PWTd). The formula usedfor estimation of LVM from LV linear dimensions is based on modeling the LV as a prolate ellipse, and assumes that the major/minor axis ratio is $2: 1$ (Lang et al., 2015).

LVM $=0.8 \times\{1.04[($ LVIDd + PW + IVSd $) 3$ - (LVIDd)3] $\}+0.6$ g.

Left ventricular mass was indexed to body surface area (BSA).

Left ventricular mass index (LVMI) was calculated as the ratio of LVM to body surface area $(\mathrm{g} / \mathrm{m} 2)$.

Subjects were considered to have LVH if LVMI was more than $115 \mathrm{~g} / \mathrm{m} 2$ for men and more than $95 \mathrm{~g} / \mathrm{m} 2$ for women (Nagueh et al, 2009).

\section{LV stiffness index:}

Tissue Doppler diastolic velocities were measured from the septal, lateral, inferior, and anterior mitral annuli in the 2- and 4-chamber views and averaged. The following measurements were recorded: early diastolic velocity (e') and late diastolic velocity $\left(\mathrm{a}^{\prime}\right)$ and their ratio $\left(\mathrm{e}^{\prime} / \mathrm{a}^{\prime}\right)$. The ratio of early diastolic mitral inflow velocity (E) to tissue Doppler imaging (TDI) e' (E/e'), which correlates with diastolic filling pressure, was considered .

E/e': the normal E/e' ratio from the medial annulus is $<8$ and suggests a normal left atrial pressure. Whil(Lang et al., 2015).

Diastolic stiffness was assessed with the use of three indices E, $\mathrm{e}^{\prime}$ and the LVEDD. The ratio (E/ e') represents an index of LV filling pressure and LVEDD was used as an index of ventricular volume. The ratio of these two parameters, (E/ e')/LVEDD, provides a new index of diastolic stiffness and this was measured for subjects in the study (King et al., 2008).

\section{Interatrial dyssynchrony measurement:-}

Pulsed-wave tissue Doppler recordings were obtained in the apical four -chamber view with the sample volume placed at the lateral aspect of the mitral annulus and the tricuspid annulus to measure the peak early and late diastolic mitral ( $\left.E^{\prime}(M), A^{\prime}(M)\right)$ and tricuspid $\left(E^{\prime}(T), A^{\prime}(T)\right.$ ) annular velocities (Quinones et al., 2002).

The time was measured from initiation of the $\mathrm{P}$ wave on the ECG to the beginning of the late diastolic TDI signal at the lateral border of the mitral annulus $\left(\mathrm{P}^{-} \mathrm{A}^{\prime}(\mathrm{M})\right)$ and the tricuspid annulus $\left(\mathrm{P}-\mathrm{A}^{\prime}(\mathrm{T})\right)$. Interatrial dyssynchrony was defined as prolongation if the difference between the $\mathrm{P}-\mathrm{A}^{\prime}(\mathrm{M})$ and $\mathrm{P}-\mathrm{A}^{\prime}(\mathrm{T})$ intervals more than $106.3+40.8 \mathrm{~ms}$. All Doppler measurements were calculated as the average over three beats (Eicher et al., 2012).

Left atrial volumes and functions:-

Using2D imaging, LA volumes were measured using area-length technique. (Lang et al., 2015).

The following equation used in measuring LA volume:-

LA volume $=0.85 X($ A1XA2 $) \backslash L$.

(A1) area of LA in apical four chamber view.

(A2) area of LA in apical two chamber view.

(L) is the shortest atrial long axis in apical two andfour chamber views

Left atrial volumes were measured as following:-

1. Maximum volume (Vmax) at the end of systole just before opening of mitral valve. 
2. Minimum volume (Vmin) at end diastole, the time at which the atrium reach its nadir just before mitral valve closure.

These volumes were used to assess LA functions:

1. LA maximum volume index $(\mathrm{LA} \max \mathrm{VI})=\mathrm{Vmax} / \mathrm{BSA}$.

2. LA total stroke volume $(\mathrm{TSV})=\mathrm{Vmax}-\mathrm{V} \min$.

\section{Statistical analysis:-}

Data from categorical variables were compared using Chi square or Fisher exact test. Data from continuous variables were summarized as mean and standard deviation (SD). Comparison between groups was done using independent sample $t$-test and one way ANOVA test. Pearson's correlation coefficients were calculated to evaluate the relationship between variables.

Two-tailed $p$ value $<0.05$ was considered statistically significant $p$ value $<0.001$ was considered statistically highly significant. All statistical analyses were done using SPSS version 21.0 software for windows (SPSS Inc. Chicago, IL).

\section{Result:-}

Demographic data , risk factors: (Table 1)

This study consisted of 304 subjects classified into two groups:

Group I: high normal blood pressure group which included 158 subjects whose blood pressure range (130-139/85$89 \mathrm{mmHg}$ ).

Group II: normal blood pressure group: this group included 146 subjects with blood pressure $(<130 / 85 \mathrm{mmHg})$.

Table 1:-Demographic data and risk factors and kidney function test.

\begin{tabular}{|c|c|c|c|c|c|c|}
\hline \multicolumn{2}{|l|}{ Variable } & $\begin{array}{l}\text { Total population } \\
\mathrm{N}=304 \\
\text { Mean+SD } \\
\mathrm{N}(\%)\end{array}$ & $\begin{array}{l}\text { Group I } \\
\text { PHN } \\
\mathrm{N}=158 \\
\text { Mean+SD } \\
\mathrm{N}(\%)\end{array}$ & $\begin{array}{l}\text { Group II } \\
\text { Normotensive } \\
\mathrm{N}=146 \\
\text { Mean+SD } \\
\mathrm{N}(\%)\end{array}$ & $\mathrm{T}$ & P-value \\
\hline \multicolumn{2}{|l|}{ Age } & $57.03+7.831$ & $57.91+7.349$ & $50.91+8.224$ & 1.280 & $\begin{array}{l}> \\
(\mathrm{NS})\end{array}$ \\
\hline \multicolumn{2}{|l|}{ BMI } & $26.37+1.96$ & $26.35+1.96$ & $26.39+1.98$ & 0.246 & $\begin{array}{ll}> & 0.05 \\
(\mathrm{NS})\end{array}$ \\
\hline \multicolumn{2}{|l|}{ Variable } & $\mathrm{N}(\%)$ & $\mathrm{N}(\%)$ & $\mathrm{N}(\%)$ & $\begin{array}{l}\text { Chi- } \\
\text { square }\end{array}$ & P-value \\
\hline \multirow[t]{2}{*}{ Gender } & Male & $68(65.7 \%)$ & $42(72.4 \%)$ & $26(56.5 \%)$ & \multirow[b]{2}{*}{2.863} & \multirow{2}{*}{$\begin{array}{l}>0.05^{\mathrm{F}} \\
(\mathrm{NS})\end{array}$} \\
\hline & Female & $36(34.3 \%)$ & $16(27.6 \%)$ & $20(43.5 \%)$ & & \\
\hline \multicolumn{3}{|c|}{ Serum creatinine } & $0.97+0.199$ & $0.90+0.159$ & 1.446 & $\begin{array}{l}>\quad 0.05 \\
(\mathrm{NS})\end{array}$ \\
\hline \multicolumn{3}{|l|}{ eGFR } & $91.72+23.22$ & $106.07+24.11$ & 2.293 & $\begin{array}{l}<0.05 \\
(\mathrm{~S})\end{array}$ \\
\hline \multicolumn{3}{|c|}{ Microalbuminuria } & $44.09+41.89$ & $28.40+21.37$ & 1.848 & $\begin{array}{l}<0.05 \\
(\mathrm{NS})\end{array}$ \\
\hline
\end{tabular}

SD: Standard deviation; (S) significant: (P value < 0.05); (HS)highly significant (P value < 0.001); (NS)nonsignificant: $(\mathrm{P}$ value $>0.05)$

There were no statistically significant difference between the two groups as regard the demographic data and risk factors (age, BMI ,gender andserum creatinin ) $(\mathrm{P}>0.05)$. Both groups had statistically significant difference as regard to eGFR and micro-albuminuria $(\mathrm{p}<0.05)$ Table $(1)$ 
Table 2:-Comparison of ECG data in the two groups.

\begin{tabular}{|c|c|c|c|c|c|}
\hline Variable & $\begin{array}{l}\text { Total population } \\
=304 \\
\text { Mean+SD } \\
\mathrm{N}(\%)\end{array}$ & $\begin{array}{l}\text { Group I } \\
\text { PHN } \\
\mathrm{N}=158 \\
\text { Mean+SD } \\
\mathrm{N}(\%)\end{array}$ & $\begin{array}{l}\text { Group II } \\
\text { Normotensive } \\
\mathrm{N}=146 \\
\text { Mean+SD } \\
\mathrm{N}(\%)\end{array}$ & $\mathrm{T}$ & p-value \\
\hline QT dispersion & $50.20+19.55$ & $54.83+19.97$ & $43.04+16.58$ & 3.145 & $<0.05(\mathrm{~S})$ \\
\hline VAT & $43.61+627$ & $45.60+6.63$ & $41.09+5.77$ & 3.653 & $\begin{array}{l}<0.001 \\
(\mathrm{HS}) \\
\end{array}$ \\
\hline LVH Cornell & $12.93+4.685$ & $13.25+4.768$ & $11.54+4.603$ & 0.759 & $<0.05(\mathrm{NS})$ \\
\hline
\end{tabular}

SD: Standard deviation; (S) significant: (P value < 0.05); (HS)highly significant (P value < 0.001); (NS)nonsignificant: ( $\mathrm{P}$ value $>0.05$ ).

Table 3:-ROC analysis of QT dispersion showing, AUC, best cutoff, Sensitivity and specificity values (Diagnostic Accuracy) to predict left ventricular hypertrophy

\begin{tabular}{|l|l|l|l|}
\hline \multirow{2}{*}{ QT dispersion } & AUC & Best COV & P-value \\
\cline { 2 - 4 } & 0.680 & $>40$ & 0.0005 \\
\hline Diagnostic Accuracy & 76.27 & 95\% CI & \\
\hline Sensitivity\% & 57.78 & $63.4-86.4$ & \\
\hline Specificity\% & 70.3 & $42.2-72.3$ \\
\hline PPV & 65.0 & $57.5-81.2$ & \\
\hline NPV & $48.3-79.4$ & \\
\hline
\end{tabular}

AUC: Area under the curve, COV: Cutoff value, CI: Confidence interval ,PPV: positive Predictive value, NPV: Negative Predictive value.

*cutoff point of QT dispersion > $40 \mathrm{~ms}$ indicate presence of $\mathrm{LVH}$ with sensitivity $=\mathbf{7 6 . 2 6} \&$ specificity $=57.78$

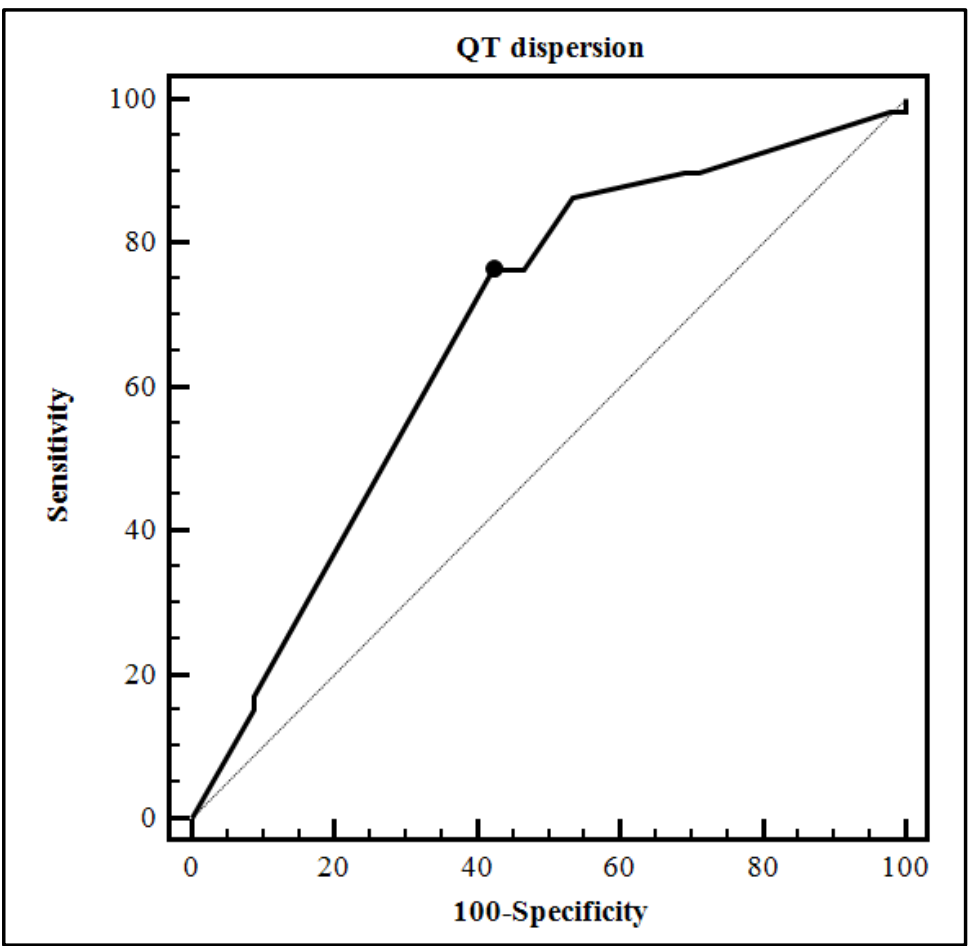

Figure 1:- ROC curve shows sensitivity and specificity of QTd in prediction of LVH. 
Table 4:-Comparison of Echocardiographic data in two groups.

\begin{tabular}{|c|c|c|c|c|}
\hline Variables & $\begin{array}{l}\text { Group I } \\
\text { PHN } \\
\mathrm{N}=158 \\
\text { Mean+SD } \\
\mathrm{N}(\%)\end{array}$ & $\begin{array}{l}\text { Group II } \\
\text { Normotensive } \\
\mathrm{N}=146 \\
\text { Mean+SD } \\
\mathrm{N}(\%)\end{array}$ & $\mathrm{T}$ & p-value \\
\hline left ventricular mass & $193.65+41.14$ & $159+35.56$ & 4.561 & $<0.001(\mathrm{HS})$ \\
\hline $\begin{array}{l}\text { left ventricular mass } \\
\text { index }\end{array}$ & $113.77+23.34$ & $92.55+20.20$ & 4.921 & $<0.001(\mathrm{HS})$ \\
\hline LA Vmax & $36.47+6.62$ & $33.27+6.29$ & 2.515 & $<0.05(\mathrm{~S})$ \\
\hline LA Vmin & $17.39+5.40$ & $14.06+5.89$ & 2.950 & $<0.05(\mathrm{~S})$ \\
\hline TSV & $19.09+3.78$ & $19.21+2.69$ & 0.175 & $>0.05(\mathrm{NS})$ \\
\hline LAVI & $21.21+3.83$ & $19.40+3.56$ & 2.455 & $<0.05(\mathrm{~S})$ \\
\hline $\begin{array}{l}\text { Inter-atrial } \\
\text { dyssynchrony }\end{array}$ & $31.34+10.464$ & $26.39+7.476$ & 2.812 & $<0.05(\mathrm{~S})$ \\
\hline Ele' & $7.61+2.30$ & $6.07+1.65$ & 3.962 & $<0.001(\mathrm{HS})$ \\
\hline LV stiffness index & $1.50+0.429$ & $1.27+0.334$ & 3.097 & $<0.05(\mathrm{~S})$ \\
\hline
\end{tabular}

SD: Standard deviation; (S) significant: (P value < 0.05); (HS)highly significant (P value < 0.001); (NS)nonsignificant: ( $\mathrm{P}$ value $>0.05)$.

Compared to participants with optimal BP, those with prehypertension had a nominally higher prevalence of abnormal LV geometry (increased LVMI )cutoff point of QT dispersion > 40 msindicate presence of increased LVMI withsensitivity $\mathbf{= 7 6 . 2 6} \&$ specificity $\quad \mathbf{= 5 7 . 7 8}$.

The mean adjusted LV mass was significantly greater in prehypertensive $\left(193.65+41.14 \mathrm{~g} / \mathrm{m}^{2} \mathrm{vs}\right.$. $159+35.56$; $\mathrm{p}<0.001)$. A diagnosis of increased LVM by ECG was significantly more frequent overall, among cases, compared to controls $(13.25+4.768 \%$ vs. $11.54+4.603 ; \mathrm{p}<0.05(\mathrm{~S}))$ Table $(2-3)$

Parameters of diastolic function were progressively worse in prehypertension in comparison with optimal BP (Table 4). LA volume was higher in those with prehypertension. QTD, Max LAV , and inter atrial dyssynchronywere correlated with most of parameters of LV remodeling and diastolic functionTable(4-5)

Correlations in high normal blood pressure group(group I):

Table 5:-show correlations of LVMI with QTd, LA Vmax and interatrial dyssynchrony in group I.

\begin{tabular}{|l|l|l|l|}
\hline Item & Group I & R & P value \\
\hline \multirow{4}{*}{ LVMI } & QTd & 0.481 & $<0.001(\mathrm{HS})$ \\
\cline { 2 - 4 } & Interatrial dyssynchrony & 0.256 & $<0.001(\mathrm{HS})$ \\
\cline { 2 - 4 } & LA Vmax & 0.613 & $<0.001(\mathrm{HS})$ \\
\hline
\end{tabular}

(S) significant: $(\mathrm{P}$ value $<0.05)$; $($ HS)highly significant $(\mathrm{P}$ value $<0.001)$; $($ NS)non-significant: $(\mathrm{P}$ value $>0.05)$.

Discussion , $\quad$ This prospective study was carried out in cardiology department, Zagazig University in the period from August 2014 to October 2015. This study included two groups classified by ambulatory BP to exclude masked hypertension as:Prehypertensive G1and control G11.

To investigate the extent to which prehypertension may be associated with preclinical target organ damage, , we comprehensively investigated the association of prehypertension with parameters of left ventricular (LV) structure and function .

Microalbuminuria and eGFR were also used as another example of TOD in patients with high normal blood pressure. correlation between a simple ECG parameter (QTd), and increased LVMI . Interatrial dyssynchrony and decreased LA function, observed in early stages of diastolic dysfunction with preserved ejection fraction, were studied in our work as predictors that may lead to diastolic dysfunction in prehypertensives.

Increased LVMI as compensatory mechanism for ventricular pressure overload, hyperkinetic status and increased total peripheral resistance (TPR) (Chahal et al., 2010) is an independent risk factor for CV morbidity and mortality in hypertensive individuals (Brown et al., 2000). The present study showed higher indices of increased LVM and 
LVMI in the high normal blood pressure subjects. Manioset al. documented similar findings of higher LVM in prehypertensives than in normotensives, even after adjusting for covariates (Manios et al., 2009)

There is evidence that increasing QTd on the ECG represents regional differences in myocardial recovery of excitability and this may act asarrhythmogenic substrate(Ale et al., 2013).

The current study showed significant higher QTd values in subjects with high normal blood pressure than normotensives. These results are similar to the report by (Dogru et al., 2009).

Using ROC curve, QTd cutoff $>40$ mspoint has sensitivity $76.3 \%$ and specificity $57.7 \%$ in predicting increased LVMI .

The current study also concluded that prolongation of the VAT is associated with diastolic dysfunction in prehypertensive persons. This was concluded from a direct moderate significant correlation between VAT and LV stiffness index which indicate that prolongation in VAT is associated with diastolic dysfunction. These results were similar to what discovered by Boles et al., (Boles et al., 2010).

Adelayed interatrial conduction could have important haemodynamic consequences which was approved by this study would lead to delayed onset of pre-systolic filling, shorten the interval between LA contraction and mitral valve closure, and modify the effect of left atrial 'kick'. The two atria would be contracting less synchronously than normal so that interatrial septal compliance would be different.Furthermore, if sufficiently delayed, LA contraction could occur against a closing mitral valve, which is precisely what was observed in diastolic dysfunction with preserved ejection fraction patients(Ariyarajah \& Spodick, 2006).

In this study LA volumes increased while LA functions deteriorate in high normal blood pressure stage this was associated also with interatrial conduction delay, these results may provide explanation of signs and symptoms related to diastolic dysfunction which occur in those individuals .(Rizzo et al., 2000).

In our result there was significant positive correlation between albuminuria and LVMI may indicate similar progressive damage of hypertension on multiple organs, in the heart (increased left ventricular mass) and kidney (albuminuria) in prehypertensive group .

These data suggested that subclinical abnormalities in the kidney and vascular endothelium might precede the progression to higher BP levels. Screening for MA may identify a subgroup of patients who are at high risk for developing CVD and could benefit from early therapy and closer follow-up. (Djousse et al., 2008).

Conclusion, increased efforts regarding education, detection, and treatment could be important in management ofpre hypertension and cardiovascular disease risk prevention.

\section{References:-}

1. Ale, O. K., Ajuluchukwu, J. N., Oke, D. A., \& Mbakwem, A. C. (2013): QT dispersion in hypertensive Nigerians with and without left ventricular hypertrophy. West Afr J Med, 32(1), 57-61.

2. Antonakis, V., Tsioufis, C., Tsiachris, D., Andrikou, I., Fantaki, M., Dagres, N., ... Stefanadis, C. (2014): Associations of hemodynamic load and ventricular repolarization in patients with newly diagnosed essential hypertension: a long-term follow-up study. J Clin Hypertens (Greenwich), 16(3), 219-224.

3. Ariyarajah, V., \& Spodick, D. H. (2006): The Bachmann Bundle and interatrial conduction. Cardiol Rev, 14(4), 194-199.

4. Armstrong, A. C., Gidding, S., Gjesdal, O., Wu, C., Bluemke, D. A., \& Lima, J. A. (2012): LV mass assessed by echocardiography and CMR, cardiovascular outcomes, and medical practice. JACC Cardiovasc Imaging, 5(8), 837-848.

5. Boles, U., Almuntaser, I.,Brown, A., Murphy, R., Mahmud, A., and Feely, J., (2010): Ventricular Activation Time as a Marker for Diastolic Dysfunction in Early Hypertension. J Am Hypertens, 23:781-785.

6. Brown, D. W., Giles, W. H., \& Croft, J. B. (2000): Left ventricular hypertrophy as a predictor of coronary heart disease mortality and the effect of hypertension. Am Heart J, 140(6), 848-856.

7. Chahal, N. S., Lim, T. K., Jain, P., Chambers, J. C., Kooner, J. S., \& Senior, R. (2010): Ethnicity-related differences in left ventricular function, structure and geometry: a population study of UK Indian Asian and European white subjects. Heart, 96(6), 466-471. 
8. Cockcroft, D. W., \& Gault, M. H. (1976): Prediction of creatinine clearance from serum creatinine. Nephron, 16-)1,(31-41.

9. Djousse, L., Kochar, J., Hunt, S. C., North, K. E., Gu, C. C., Tang, W., . . . Devereux, R. B. (2008): Relation of albuminuria to left ventricular mass (from the HyperGEN Study). Am J Cardiol, 101(2), 212-216.

10. Dogru, M. T., Guneri, M., Tireli, E., Sahin, O., Celik, T., \& Iyisoy, A. (2009): QT interval and dispersion differences between normal and prehypertensive patients: effects of autonomic and left ventricular functional and structural changes. Anadolu Kardiyol Derg, 9(1), 15-22.

11. Eicher, J. C., Laurent, G., Mathe, A., Barthez, O., Bertaux, G., Philip, J. L., . . . Wolf, J. E. (2012): Atrial dyssynchrony syndrome: an overlooked phenomenon and a potential cause of 'diastolic' heart failure. Eur $J$ Heart Fail, 14(3), 248-258.

12. James, P. A., Oparil, S., Carter, B. L., Cushman, W. C., Dennison-Himmelfarb, C., Handler, J., .. . Ortiz, E. (2014): 2014 evidence-based guideline for the management of high blood pressure in adults: report from the panel members appointed to the Eighth Joint National Committee (JNC 8). JAMA, 311(5), 507-520.

13. King,G.J., Murphy,R.T., Almuntaser,I., Bennett, K., Ho,E., Brown, A.S. (2008): Alterations in myocardial stiffness in elite athletes assessed by a new Doppler index. Heart 2008;94:1323-1325.

14. Lang, R. M., Badano, L. P., Mor-Avi, V., Afilalo, J., Armstrong, A., Ernande, L., . . Voigt, J. U. (2015): Recommendations for cardiac chamber quantification by echocardiography in adults: an update from the American Society of Echocardiography and the European Association of Cardiovascular Imaging. Eur Heart J Cardiovasc Imaging, 16(3), 233-270.

15. Manios, E., Tsivgoulis, G., Koroboki, E., Stamatelopoulos, K., Papamichael, C., Toumanidis, S., . . . Zakopoulos, N. (2009): Impact of prehypertension on common carotid artery intima-media thickness and left ventricular mass. Stroke, 40(4), 1515-1518.

16. Mirvis, D.M. and Goldberger,A.L.(2015) : Electrocardiography. In :. Braunwald's Heart Disease 10th Ed. Libby P., Bonow R.O., Mann D.L., and Zipes D.P., eds. Philadelphia: Saunders Elsevier; 127-131.

17. Nagueh, S. F., Appleton, C. P., Gillebert, T. C., Marino, P. N., Oh, J. K., Smiseth, O. A., . . Evangelista, A. (2009): Recommendations forthe evaluation of left ventricular diastolic function by echocardiography. J Am Soc Echocardiogr, 22(2), 107-133.

18. Quinones, M. A., Otto, C. M., Stoddard, M., Waggoner, A., Zoghbi, W. A., Doppler Quantification Task Force of the, Nomenclature, \& Standards Committee of the American Society of, Echocardiography. (2002): Recommendations for quantification of Doppler echocardiography: a report from the Doppler Quantification Task Force of the Nomenclature and Standards Committee of the American Society of Echocardiography. J Am Soc Echocardiogr, 15(2), 167-184.

19. Rakowski, H., Appleton, C., Chan, K.L., Dumesnil, J.G., Honos, G., Jue, J., . . . Tomlinson, C. (1996): Canadian consensus recommendations for the measurement and reporting of diastolic dysfunction by echocardiography: from the Investigators of Consensus on Diastolic Dysfunction by Echocardiography. $J$ Am SocEchocardiogr 1996; 9:736-760.

20. Rizzo, V., Maio, F. D., Campbell, S. V., Tallarico, D., Petretto, F., Lorido, A., . . Carmenini, G. (2000): Left ventricular function, cardiac dysrhythmias, atrial activation, and volumes in nondipper hypertensive individuals with left ventricular hypertrophy. Am Heart J, 139(3), 529-536.

21. Sahu, P., Lim, P. O., Rana, B. S., \& Struthers, A. D. (2000): QT dispersion in medicine: electrophysiological holy grail or fool's gold? QJM, 93(7), 425-431. 